\title{
Reliability and Characterization of Nanosilver Joints Prepared by a Time-Reduced Sintering Process
}

\author{
Jingru Dai, Jianfeng Li, Pearl Agyakwa, Martin Corfield and Christopher Mark Johnson, Member, IEEE
}

\begin{abstract}
This study investigates the power cycling reliability of nanosilver sintered joints formed by a time-reduced sintering process, designed for use on a die bonder. A range of sintering parameters, reflecting different levels of manufacturability, were used to produce sintered joints in respect of shear strength and porosity, within a process cycle time of a few seconds. The reliability of the sintered attachments were evaluated against Pb5Sn solder joints under constant temperature swing power cycling conditions over the range 50 to $200{ }^{\circ} \mathrm{C}$. The thermal performance and microstructural changes of the sintered joints were monitored and evaluated non-destructively at regular intervals using transient thermal impedance and $X$-ray computed tomography. The results show that sintered joints with higher shear strengths $(>50 \mathrm{MPa})$ and lower porosities $(<25 \%)$ tend to maintain their thermal performance up to $\sim 100 \mathrm{k}$ power cycles before gradual degradation occurs. Sintered joints with intermediate shear strengths $(20$ to $40 \mathrm{MPa})$ and with corresponding analogous porosities ( 35 to 51 \%) also demonstrated comparable power cycling behavior; exhibiting a progressive decrease in effective thermal conductivity with increasing cycles. The evaluated lifetime of sintered joints with the highest shear strengths were found to be at least double those for the lower shear strength joints, and up to fourteen times those of a Pb5Sn solder die attachment. Even the most porous sintered joints exhibited lifetimes appreciably longer than a Pb5Sn die attachment. Degradation in thermal resistance was seen to correlate with observed microstructural changes, with a dependence on initial sintering parameters.
\end{abstract}

Index Terms - Sintered joints, power cycling, thermal conductivity, microstructure evolution and degradation mechanisms.

\section{INTRODUCTION}

$\mathrm{W}$ IDE band gap (WBG) devices have higher switching speeds and lower on-state losses than similarly rated

Manuscript received October 21, 2020. This research has received funding from the UK Engineering and Physical Sciences Research Council through research grants EP/K035304/1 and EP/R004501/1 and funding from the Clean Sky 2 Joint Undertaking under the European Union's Horizon 2020 research and innovation program under grant agreement No 945535. (Corresponding author: Jingru Dai.)

J. Dai, P. Agyakwa, M. Corfield and C. M. Johnson are with the Department of Electrical and Electronic Engineering, University of Nottingham, Nottingham NG7 2RD, U.K. (e-mail: jingru.dai2@exmail.nottingham.ac.uk; pearl.agyakwa@nottingham.ac.uk; martin.corfield@nottingham.ac.uk; mark.johnson@nottingham.ac.uk)

J. Li, was with University of Nottingham, Nottingham NG7 2RD, UK. He is now with with the Times Electric Innovation Centre of CRRC, Birmingham, U.K. (e-mail: jianfeng.li@teic.crrczic.cc).
Si-based power semiconductors, and therefore have significant advantages for the development of next generation power conversion systems [1-4]. Die-attach materials for packaging $\mathrm{SiC}$ or $\mathrm{GaN}$ dies are nominally required to operate at temperatures higher than $175{ }^{\circ} \mathrm{C}$, while maintaining high reliability throughout their service lifetime. Proposed high temperature approaches to die attach include high temperature solder alloys, such as $\mathrm{ZnAl}$ and AuGe [5-8], transient liquid phase bonding (TLP) [9-11] and sintered silver or copper particles [12-15]. Among these, silver sintering is widely accepted as a promising packaging technology to fulfil the reliability requirements of higher density/high temperature power electronic applications. Unlike solder attachments produced via melting and solidification, sintered $\mathrm{Ag}$ attachments have the key advantage of low processing temperatures yet high operation temperatures, together with higher electrical and thermal conductivity.

Sintering of micro-scaled silver particles generally requires the application of an external mechanical pressure of between 30 to $50 \mathrm{MPa}$ for a few minutes in order to reduce the sintering temperature to below $300{ }^{\circ} \mathrm{C}$ [16]. With the introduction of nanosilver pastes, lower pressures and even 'pressureless' sintering are achievable, with sintering times typically ranging from a few minutes to a few hours $[13,17]$. There have been rigorous studies into the formulation of nanosilver pastes $[18$, 19], the effects of surface condition of substrates (metallization and surface topography) [20-22] and the optimization of processing parameters $[23,24]$ including how these relate to reliability, generally in terms of shear strength.

The optimization and simplification of the sintering process, including reducing processing time, are critical for its uptake within industry, particularly as these parameters relate to efficiency, low cost and ease of implementation. In particular, the processing times for bonding on the basis of one die/substrate at a time are unfeasibly long in comparison to the conventional solder reflow process, where multiple components can be assembled in parallel in one process step. However, to date, the benefits of reduced sintering processing times have received little attention. This may be due to unavailability of sintering equipment (e.g. hydraulic press) that is capable of the simultaneous application of heat and load to multiple components. Our previous study [25] has demonstrated a route for rapid die attachment by using a time-reduced sintering process for dry nanosilver film with a manufacturing cycle time of a few seconds. However, the 
reliability and thermal performance of such joints prepared within short processing times remain unsubstantiated.

In general, the failure mechanism of sintered joints has been associated with microstructural coarsening, the formation and development of cracks/voids and interfacial delamination [26-28]. Crack and void formation is understood to be related to thermally-driven, continued densification of silver occurring during temperature cycling [29, 30]. The influence of the surface topography of the bonding surfaces on the quality of attachment achieved has also been reported previously [20,21]. However, few studies have linked the substrate surface condition to the heterogeneity of as-sintered microstructures and their subsequent evolution during temperature cycling. Thus, a deeper understanding of how sintering parameters and conditions influence this mechanism is required.

The specific objectives of this paper are: 1) to compare the thermal performance, during power cycling, of sintered die attachments having a range of bonding strengths and/or microstructural porosities, and to compare these with a $\mathrm{Pb} 5 \mathrm{Sn}$ solder joint; 2) to concurrently monitor the microstructural evolution of sintered joints throughout the power cycling period and correlate any change with thermal performance, using a non-destructive 'same-sample' approach; 3) to elucidate the degradation and failure mechanisms of sintered joints by a time-reduced sintering process during power cycling; and to identify and understand any concessions between the two.

\section{EXPERIMENTAL PROCEDURES}

\section{A. Materials and sample preparation}

The power devices used were CREE CPW4-1200-S010B $\mathrm{SiC}$ diodes with a footprint of $2.26 \mathrm{~mm} \times 2.26 \mathrm{~mm} \times 0.377 \mathrm{~mm}$ in size. These devices have $\sim 1.4 \mu \mathrm{m}$ thick Ni/Ag metallization on the cathode (back side) and $\sim 4 \mathrm{~m}$ thick Al metallization on the anode (top side). The AlN-based substrates were custom-manufactured by DOWA Metaltech Co., Ltd (Tokyo, Japan). They consisted of $1 \mathrm{~mm}$-thick AlN ceramic tile sandwiched between $0.3 \mathrm{~mm}$-thick $\mathrm{Cu}$ tracks, actively brazed on both sides. The finish on each substrate, for sintered die attachments, was $0.2 \mu \mathrm{m}$ thick $\mathrm{Ag}$ while for $\mathrm{Pb} 5 \mathrm{Sn}$ soldered die attachments was $5 \mu \mathrm{m}$ thick NiP followed by $0.05 \mu \mathrm{m}$ thick $\mathrm{Au}$ on the surface. Sintering was achieved using $62.3 \mu \mathrm{m}$ thick nanosilver film, Argomax 2020, obtained from Alpha Assembly Solutions (Somerset, NJ 08873, USA) with an average particle size of $\sim 20 \mathrm{~nm}$. The Pb5Sn solder alloy was a $0.1 \mathrm{~mm}$ thick preform, obtained from Semelab Limited,
TT-Electronics (Lutterworth, UK).

One $\mathrm{SiC}$ diode was attached onto each substrate. The sintering process was carried out using a Datacon 2200 EVO die bonder. The process begins with transfer of the nanosilver film onto the backside of a diode by a pick-and-place (pp) tool. The die $\&$ film are then placed onto a substrate, preheated to the required bonding temperature. With the touchdown of the die, the $\mathrm{pp}$ tool is rapidly heated to the sintering temperature and a force of up to $100 \mathrm{~N}$ (equivalent to a maximum pressure of approximately $20 \mathrm{MPa}$ for the specified die size) applied simultaneously. Four sintering trials with different combinations of time, pressure and temperature were employed, so as to produce joints with differing levels of bonding strength/porosity. Table I displays processing parameters and shear strength and porosity values $[25,31]$. The preparation of the $\mathrm{Pb} 5 \mathrm{Sn}$ attachments consisted of a pad of $4 \mathrm{~mm} \times 4 \mathrm{~mm}$ solder preform placed between a $\mathrm{SiC}$ diode and substrate and reflowed at $350{ }^{\circ} \mathrm{C}$ for $5 \mathrm{~min}$.

Ultrasonically bonded $\mathrm{Al}$ wires with a diameter of $375 \mu \mathrm{m}$ were used to establish the necessary electrical connections. If/when wire bond lift off occurred during power cycling, new bonds were made to replace them. Bus bars, consisting of 125 $\mu \mathrm{m}$ thick silver foils were soldered to the substrates using a $\mathrm{Sn3}$.6Pb2Ag solder paste to provide external connections (see Fig. 1).

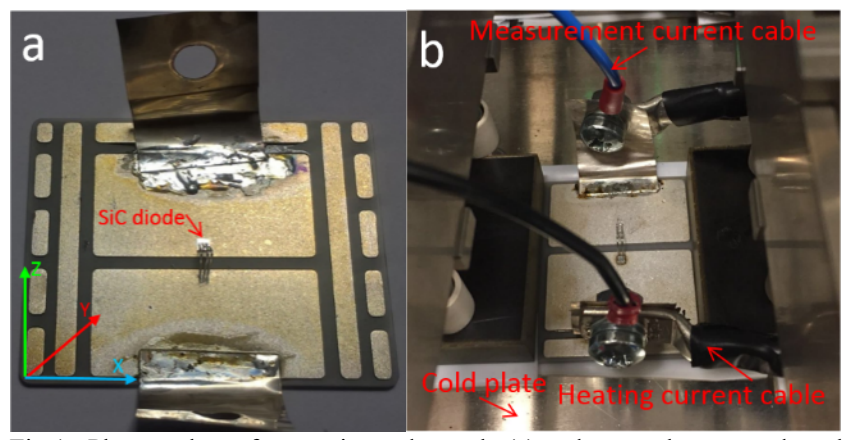

Fig.1. Photos taken of an as-sintered sample (a) and a sample mounted on the cold plate of a power tester for power cycling and thermal tests (b).

\section{B. Power cycling and transient thermal tests}

Both power cycling and transient thermal impedance tests were carried out on a Mentor Graphics ${ }^{\circledR} 1500$ A Power tester. The samples were mounted onto a cold plate, kept constant at $20{ }^{\circ} \mathrm{C}$, with two layers of $250 \mu \mathrm{m}$-thick polytetrafluoroethylene (PTFE) underneath to increase the thermal resistance, see Fig. 1b. The junction temperature $\mathrm{Tj}$ of the $\mathrm{SiC}$ diode was

TABLE I

EXPERIMENTAL TRIALS WITH SHEAR STRENGTH AND MICROSTRUCTURAL POROSITY DATA FOR POWER CYCLING TESTS

\begin{tabular}{|c|c|c|c|c|c|c|c|}
\hline \multirow{2}{*}{ Types } & \multirow{2}{*}{ Trials } & \multicolumn{3}{|c|}{ Processing parameters } & \multirow{2}{*}{ Shear strength } & \multirow{2}{*}{ True porosity } & \multirow{2}{*}{ Bondline thickness } \\
\hline & & temperature & pressure & time & & & \\
\hline \multirow{4}{*}{ Nanosilver sintered joints } & W1 & $220^{\circ} \mathrm{C}$ & $6 \mathrm{MPa}$ & $1 \mathrm{~s}$ & $20.5 \mathrm{MPa}$ & $50.9 \%$ & $32.26 \mu \mathrm{m}$ \\
\hline & W2 & $250{ }^{\circ} \mathrm{C}$ & $10 \mathrm{MPa}$ & $5 \mathrm{~s}$ & $32.4 \mathrm{MPa}$ & $43.2 \%$ & $27.8 \mu \mathrm{m}$ \\
\hline & W3 & $260{ }^{\circ} \mathrm{C}$ & $10 \mathrm{MPa}$ & $6 \mathrm{~s}$ & $40.5 \mathrm{MPa}$ & $35.5 \%$ & $24.49 \mu \mathrm{m}$ \\
\hline & W4 & $300{ }^{\circ} \mathrm{C}$ & $19.5 \mathrm{MPa}$ & $9 \mathrm{~s}$ & $52.7 \mathrm{MPa}$ & $24.7 \%$ & $20.97 \mu \mathrm{m}$ \\
\hline $\mathrm{Pb} 5 \mathrm{Sn}$ solder joint & $\mathrm{TT}$ & $350{ }^{\circ} \mathrm{C}$ & - & $5 \min$ & $\sim 25 \mathrm{MPa}$ & - & - \\
\hline
\end{tabular}

Shear strength and porosity/bondline thickness obtained from samples bonded with dummy Si dies of $2 \mathrm{~mm} \times 2 \mathrm{~mm}$. 
approximated by using the forward voltage drop (Vf) as a temperature sensitive electrical parameter (TSEP) from the calibration curve $\mathrm{Tj}=\mathrm{f}(\mathrm{Vf})$ attained under a measurement current of $50 \mathrm{~mA}$ at temperatures from $48^{\circ} \mathrm{C}$ to $197^{\circ} \mathrm{C}$ using a temperature-controlled hot-plate. The power cycling tests operated under a "constant $\Delta \mathrm{T}$ " mode by regulating the cycling current. A constant temperature swing of $150{ }^{\circ} \mathrm{C}$ was ensured, and the current on and off times were fixed at 5 and $2.5 \mathrm{~s}$ respectively, leading to a constant temperature swing between 50 to $200{ }^{\circ} \mathrm{C}$ (peak temperature variation within $\pm 7^{\circ} \mathrm{C}$ ), see Fig. 2.

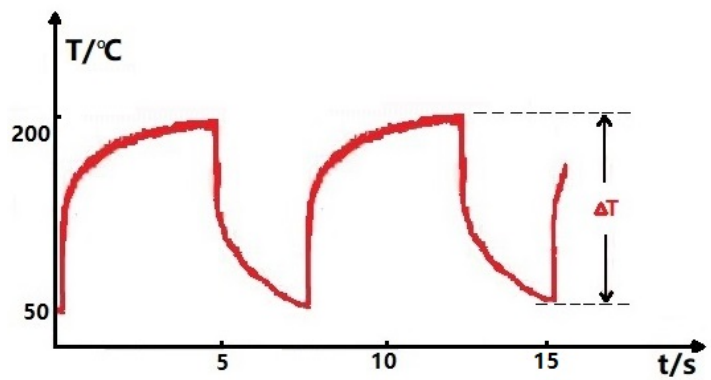

Fig. 2. Temperature-time profile of the power cycling test in constant $\Delta \mathrm{T}$ cycling mode.

Real-time thermal performance for all die attachments was characterized nondestructively using in-situ transient thermal impedance measurements for as-prepared samples and then after every $5 \mathrm{k}$ or $10 \mathrm{k}$ power cycles. During a transient thermal test, the SiC diodes were heated with a current of $6 \mathrm{~A}$ for $80 \mathrm{~s}$ to reach thermal equilibrium. After the heating current was removed, the forward voltage, Vf, at a constant current of $50 \mathrm{~mA}$, was recorded (on cooling) and converted into temperature change $(\mathrm{Tj})$ using the calibration curve. Effective thermal conductivities for the die-attach were extracted through data fitting of the estimated in-situ transient junction temperatures during the cooling stage (Fig. 3) to finite element (FE) simulation results. The thermal response of the diodes at times $\leq 10^{-3} \mathrm{~s}$ (thermal contribution of the die attachment) are not captured in the thermal tests due to inherent electrical switching transient behavior and were therefore simulated through a FE model to estimate the thermal resistance contribution from the die attachment [29]. The theoretical data (pink curve) in Fig. 3 was extrapolated from a combination of simulation results fitted to the experimental thermal response data obtained after $10^{-3} \mathrm{~s}$.

\section{Microstructure characterization}

The formation and development of cracks within the die attachments at different stages of power cycling were characterized through non-destructive 3D X-ray computed tomography (CT) carried out on a Zeiss Xradia Versa XRM-500 CT at regular power cycle intervals. Scanning parameters were selected to ensure that the entire die attachment was captured within the field of view (indicated in Fig. 4). This resulted in a spatial resolution of approximately $2.4 \mu \mathrm{m}$ using a 1024 pixel array. 1601 projections were acquired over a rotation of $180^{\circ}$ for each scan. The projections were reconstructed using Xradia-Zeiss $3 D$ Reconstructor software which uses a filtered back projection algorithm. Xradia-Zeiss $3 D$ viewer software was used to visualize the formation and development of voids/cracks, as well as obtain virtual cross-sectional images in the lateral and through-thickness planes, as illustrated in Fig. 4. Image analysis (Matlab) was used to quantify the percentage of voids/cracks within the lateral (X-Y) plane (parallel to the bond surfaces). The analysis area was fixed at $1.7 \mathrm{~mm} \times 1.7 \mathrm{~mm}$ for each dataset, for each image. In addition, the fracture surfaces of W1 samples were imaged after shear testing using a Hitachi TM3000 desktop scanning electronic microscope.

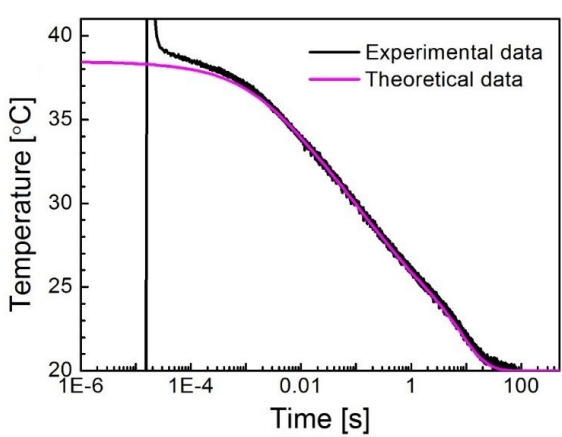

Fig. 3. Thermal curves measured during the cooling stage of a transient thermal test.

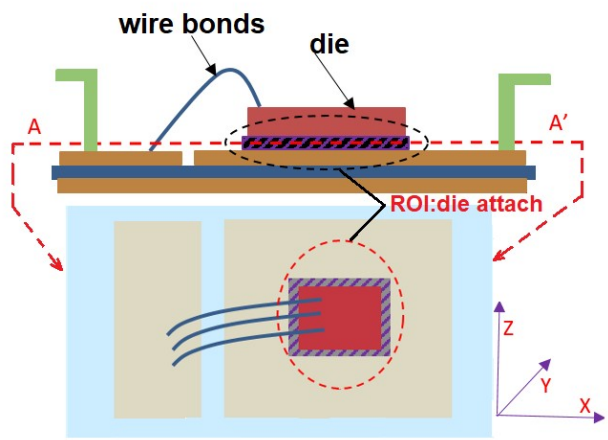

Fig.4. Schematic of cross-sectional X-Z plane and view through A-A' (X-Y plane) for damage evolution characterization.

\section{RESULTS \& DISCUSSION}

\section{A. Evolution of thermal conductivities}

Figure 5 shows that the effective thermal conductivities (extracted from the combined experimental and simulation data) for the as-sintered die attachments at zero cycles; samples $\mathrm{W} 1$, $\mathrm{W} 2, \mathrm{~W} 3$ and $\mathrm{W} 4$, are similar at approximately $100 \mathrm{~W} /(\mathrm{m} \cdot \mathrm{K})$ and nearly 2.5 times higher than for that of an as-prepared $\mathrm{Pb} 5 \mathrm{Sn}$ die attachment $(43.7 \mathrm{~W} /(\mathrm{m} \cdot \mathrm{K}))$; similar thermal conductivity values have been previously reported in [32]. The errors in the extracted effective thermal conductivities were estimated to be around 5 to $10 \%$, caused mainly by signal noise in the in-situ transient junction temperatures of the diodes during the cooling stages.

During power cycling, the effective thermal conductivity of sample W4 (with the highest shear strength/lowest porosity) 
remained relatively constant until $\sim 100 \mathrm{k}$ power cycles, before gradually decreasing to $88 \mathrm{~W} /(\mathrm{m} \cdot \mathrm{K})$ at $260 \mathrm{k}$ power cycles and further to $72 \mathrm{~W} /(\mathrm{m} \cdot \mathrm{K})$ at $303 \mathrm{k}$ power cycles, at which point the test was terminated due to the instability of the device. This slow rate of change of thermal conductivity under power cycling agrees with our previous studies on sintered attachments [29, 30]. In comparison, curves for samples W1, W2 and W3 virtually overlap, with thermal conductivity degrading more rapidly to $\sim 12.5 \mathrm{~W} /(\mathrm{m} \cdot \mathrm{K})$ after $\sim 590 \mathrm{k}$ cycles near the conclusion of the tests $(\mathrm{W} 1, \mathrm{~W} 2$ and $\mathrm{W} 3$ terminated after 576615,642415 and 636534 power cycles, respectively). In contrast, the effective thermal conductivity of the $\mathrm{Pb} 5 \mathrm{Sn}$ solder attachment decreased sharply, from $43.7 \mathrm{~W} /(\mathrm{m} \cdot \mathrm{K})$ in the as-soldered condition to $12.5 \mathrm{~W} /(\mathrm{m} \cdot \mathrm{K})$ after $63 \mathrm{k}$ power cycles (test terminated at 66039 cycles). Notwithstanding its low shear strength and high porosity, W1, in effect, conveys an evaluated lifetime which is some five times greater than for that of a $\mathrm{Pb} 5 \mathrm{Sn}$ attachment. If a $20 \%$ drop in the effective thermal conductivity is taken as the criterion for failure, the power cycling lifetimes of the sintered joints are approximated to be $281 \mathrm{k}$ power cycles (W4), 180k power cycles (W3), 142k power cycles (W2) and 109k power cycles (W1), while the lifetime of the $\mathrm{Pb} 5 \mathrm{Sn}$ attachment is estimated to be around $20 \mathrm{k}$ cycles. When the highest shear strength/lowest porosity sample (W4) is considered, this amounts to an evaluated lifetime approximately 14 times greater than the Pb5Sn attachment, a result consistent with our previously reported work [29].

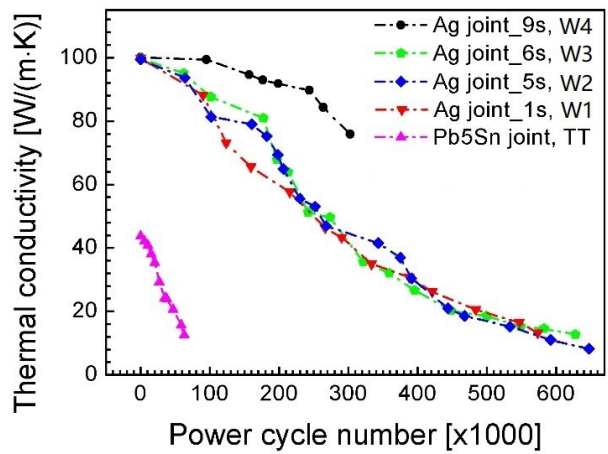

Fig. 5. Evolution of the effective thermal conductivities of die attachments during power cycling tests.

\section{B. Microstructure characterization}

\section{1) Sintered die attachments}

Figures 6 to 10 show representative X-ray CT cross-sectional images obtained from samples $\mathrm{W} 1$ to $\mathrm{W} 4$ respectively. For all the sintered joints, no obvious defects are observed in the as-sintered condition at the CT scan resolution used $(2.4 \mu \mathrm{m})$, see Figs. 6a, 7a, 8a and 9a. During power cycling, the formation and growth of cracks occur predominantly in the central regions, as opposed to at the edges. This can be readily interpreted as the highest thermal excursions generally occur directly beneath the center of the chip when forward biased. The cracks, identified to be near-vertical with respect to the through-thickness plane (X-Z planar view) develop into a network of cracks resembling a dried mud texture as power cycling tests proceed as illustrated in Fig. 10. The brighter regions/pixels immediately adjacent to large voids/cracks indicate higher localized densities, due to the higher absorption of X-rays [33]. This is considered to be associated with the continued densification of the silver under thermomechanical stress due to the mismatch of the coefficient of thermal expansion (CTE) between the die attachment layer and the chip and substrate. A detailed explanation for the formation of these cracks can be found in [29], where mechanical stress and continued densification are proposed as the basis of this cracking mechanism.

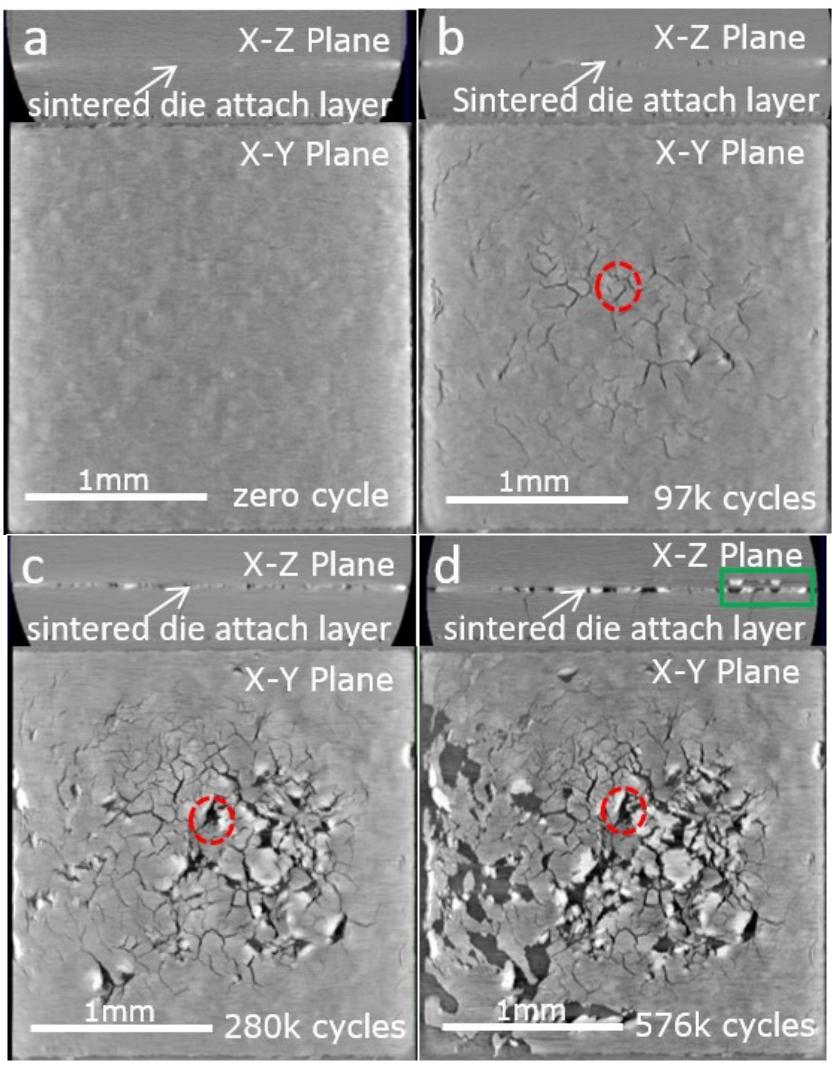

Fig. 6. X-ray CT virtual-cross-sectional images obtained from the sintered joint W1 before and after power cycling.

A number of well-developed vertical cracks ultimately develop into localized lateral cracks at the $\mathrm{Ag}-\mathrm{Cu}$ interface, as smaller cracks converge with neighboring wider cracks. The lateral cracks appear to expand with increasing number of cycles. Areas which appear brighter (greater X-ray attenuation due to higher density) surround the locally delaminated regions. It is found that localized delamination (see the red boxed area in Figs. 6c and 6d) develops much earlier in the most porous $\mathrm{Ag}$ layers (W1) i.e. after $280 \mathrm{k}$ power cycles, than in the other sintered samples. Delamination from the edges towards the center becomes more intensive with subsequent cycles. In addition, the delamination between the die/sintered layer interface appears more widespread than for that at the sintered layer/substrate interface for all sintered joints, see Fig. 10.

In Figs. 7a, 8a and 9a, a grain-like texture is apparent in the lateral cross-sections through the Ag layer of samples W2, W3 and $\mathrm{W} 4$, all of which were sintered under higher bonding 
pressures $(\geq 10 \mathrm{MPa})$, higher sintering temperatures $\left(\geq 250^{\circ} \mathrm{C}\right)$ and longer sintering times $(\geq 5 \mathrm{~s})$. There are denser Ag regions with clear outlines in the sintered condition, as apparent in the Ag layer of sample W4 where the largest bonding pressure was employed. It is interesting to note the development of cracks along the boundaries between the denser and the less dense $\mathrm{Ag}$ regions. To illustrate how the boundaries of the grain-like topographies evolve, a red circled region is traced over increasing number of cycles in Figs. 9a to 9d. The grain-like texture is postulated to result from the surface topography/grain structure of the copper. The fracture surface of sample W1 after die shear testing, as shown in Fig. 11, supports this supposition as it clearly shows grain-like morphologies and pre-cracks at the $\mathrm{Cu}$ boundaries. A non-uniform packing density of nanosilver particles can result from the non-uniform topography of the substrate, where the height variations typically follow the distribution of individual grains in the upper $\mathrm{Cu}$ layer of the substrate. As illustrated in Fig. 12, the sintered joint (black boxed region) is denser above embossed $\mathrm{Cu}$ grains, while the white boxed areas are less dense regions directly above depressed $\mathrm{Cu}$ grains or grain boundaries of the substrate.

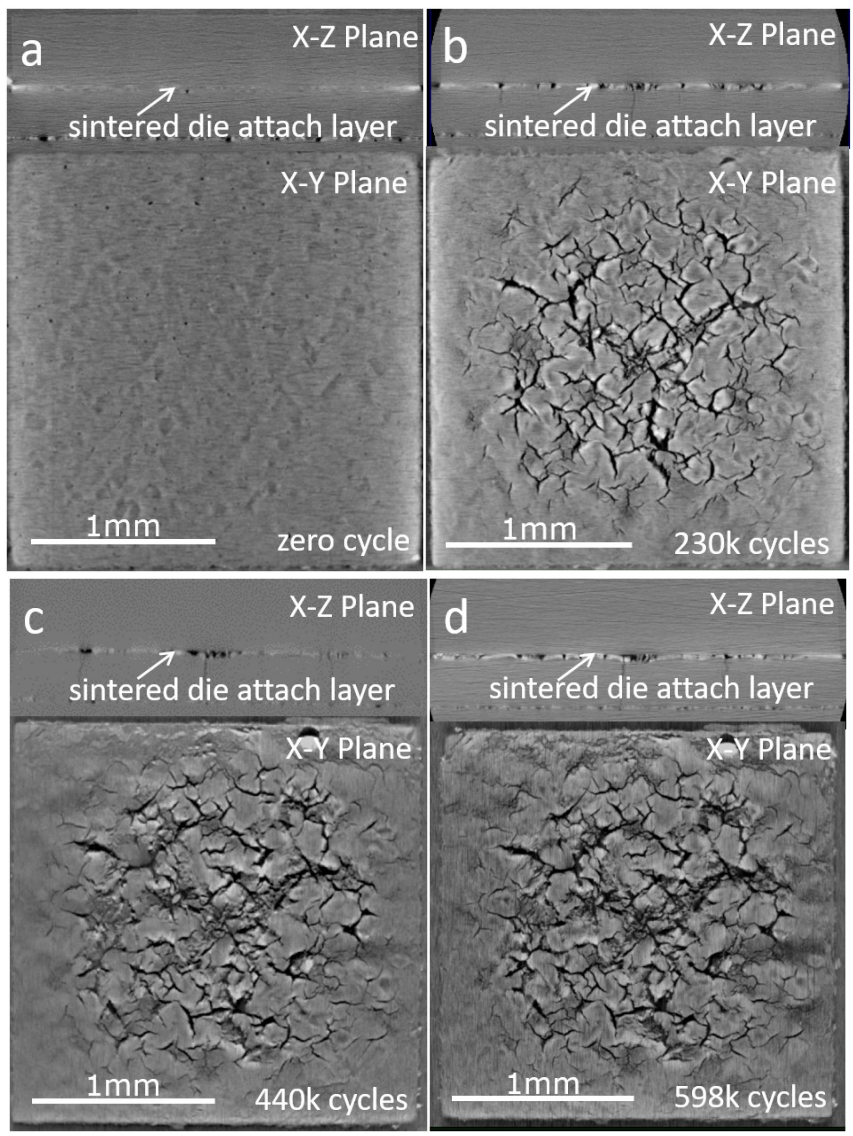

Fig. 7. Virtual X-ray CT cross-sectional images obtained from the sintered joint W2 before and after power cycling.

Sample W4, which was prepared using the highest pressure and longest time at the highest temperature, displayed the best thermal performance when compared to other samples. This may be related to its denser and more uniform microstructure. It is proposed, in line with [34], that sintered joints with low porosity are more likely to undergo continued post-sintering densification during prolonged temperature cycling, since densification occurs more readily when the microstructural density is higher and more adjacent atoms are available for inter-diffusion. Continued densification feasibly contributes to a reduction in thermal resistance by offsetting thermal resistance increases due to cracks/void formation during the early stages of power cycling. In the same way, these factors may also explain why sample W1 exhibits the shortest lifetime, as there is less opportunity for increased densification.

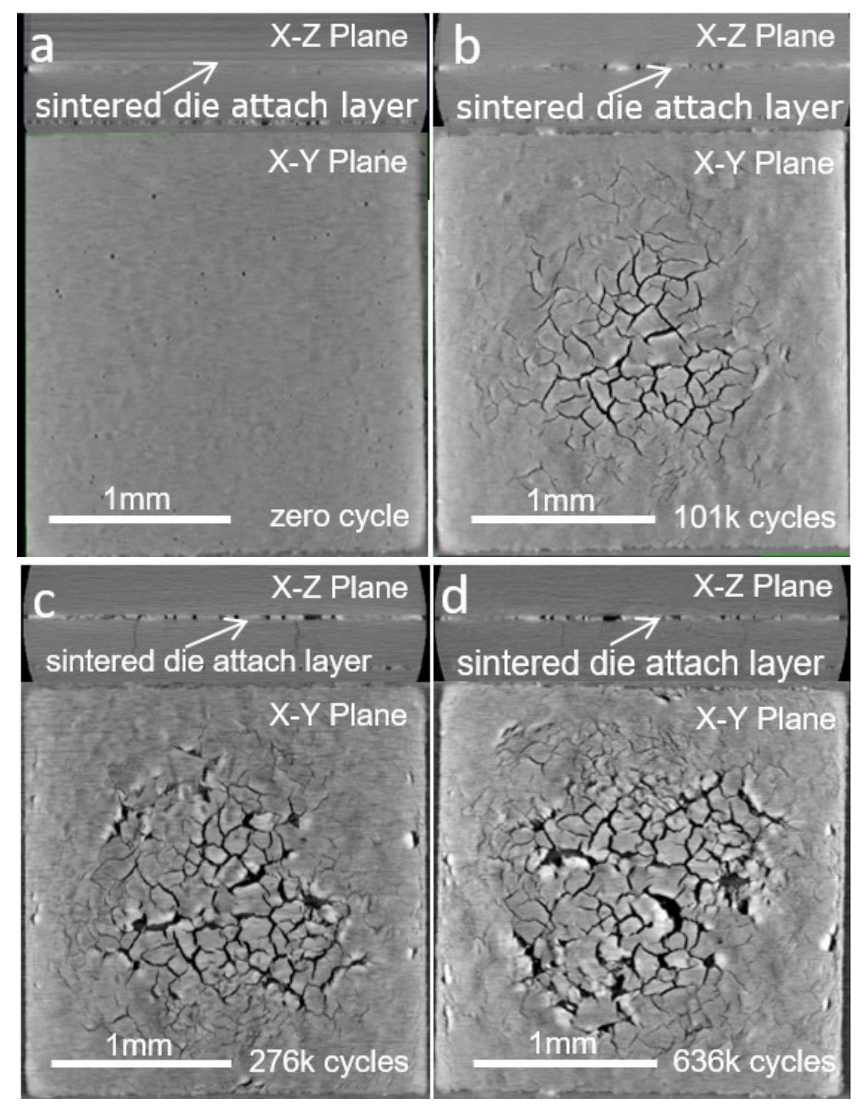

Fig. 8. Virtual X-ray CT cross-sectional images obtained from the sintered joint W3 before and after power cycling.

As presented earlier, the microstructure of the sintered joints consists of dense $\mathrm{Ag}$ regions over embossed $\mathrm{Cu}$ grains, porous regions over depressed $\mathrm{Cu}$ grains and porous boundaries over $\mathrm{Cu}$ grain boundaries. During power cycling, vertical cracks mainly form and develop in the porous regions over the $\mathrm{Cu}$ grain boundaries, of the substrate, where the packing density is low and some pre-cracks may already exist in the as-sintered layer. For the porous joints (samples W1, W2, W3) the percentage of porous regions is higher than for equivalent denser regions, leading to the conclusion that continued densification for the denser Ag regions in these samples has less impact on the development of thermal conductivity than for the lower porosity W4 sample. This is probably the reason why all the porous sintered joints have a similar thermal 
performance across the same power cycling range. In addition, local delamination appears much earlier in the most porous sintered joints, as the ratio of porous regions to that of denser regions is higher. Despite this, the sintered joints prepared at $220{ }^{\circ} \mathrm{C}$ under $6 \mathrm{MPa}$ for $1 \mathrm{~s}$, still demonstrate a significant better thermal performance and a temperature power cycling lifetime (at a temperature swing of 50 to $200{ }^{\circ} \mathrm{C}$ ) nearly 5 times longer than that of a Pb5Sn solder joint.



Fig. 9. Virtual X-ray CT images obtained from the sintered joint W4 before and after power cycling.

Figure 13 compares the percentage of cracks/voids within all samples. In the sintered samples, cracks/voids increase linearly in the region 0 to $13 \sim 16 \%$ after $\sim 300 \mathrm{k}$ power cycles, with comparable growth rates. The crack growth rate then decreases somewhat up to $\sim 520 \mathrm{k}$ power cycles from 19.6 to $21.9 \%$, before accelerating again for all samples. Sample W1 is the most characteristic with the sharpest observed increased rate in the third growth phase, which amounts to a cracked area of $27.5 \%$ after $576 \mathrm{k}$ power cycles.

\section{2) Pb5Sn soldered die attachments}

The microstructural changes observed in the $\mathrm{Pb} 5 \mathrm{Sn}$ attachment during power cycling are presented in Fig. 14. As expected under such extreme cycling temperature conditions, the initiation of voids/cracks in the $\mathrm{Pb} 5 \mathrm{Sn}$ solder joint is not restricted to the center of the bond, but develops across the entire bonded area, as evident in Figs. 14c and 14d. The largest voids form at the triple grain boundaries of the $\mathrm{Pb} 5 \mathrm{Sn}$ solder, propagating inter-granularly after $21 \mathrm{k}$ power cycles as shown in Fig. 14b. As with the sintered joints, more delamination seemingly occurs at the die/solder layer interface than at the solder/Cu interface. The voids/cracks at the interfaces appear larger than for those observed in the sintered die attachments. The percentage of voids/cracks in the soldered joint rose sharply from around $11.2 \%$ after $10 \mathrm{k}$ power cycles to $32.6 \%$ after $66 \mathrm{k}$ cycles.

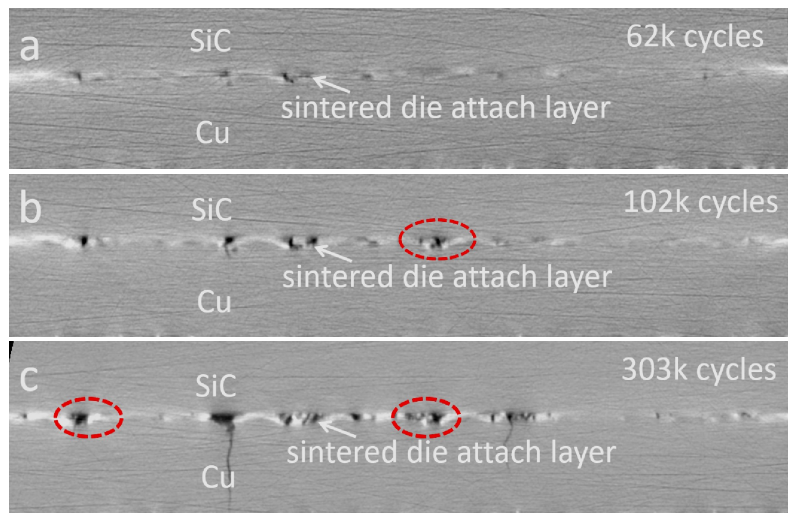

Fig. 10. Virtual X-ray CT cross-sectional images in the X-Z plane for sample W4 after different power cycling periods.

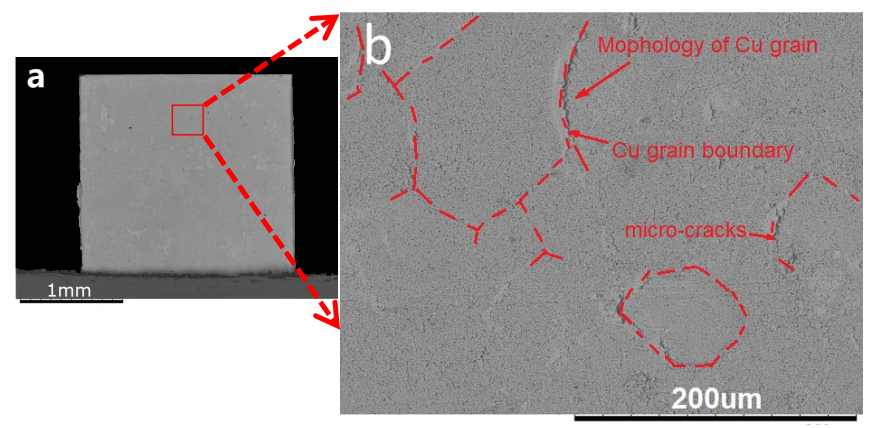

Fig. 11. SEM images taken from the fracture surface on the $2 \mathrm{~mm} \times 2 \mathrm{~mm}$ dummy Si side of W1 as-sintered joint (a) Overview of the fracture surface, and (b) Enlarged view of the red boxed area (a) showing the morphologies of $\mathrm{Cu}$ grains.

\section{Comparison between microstructure and thermal performance}

The effective thermal conductivities of all the as-sintered joints $(100 \mathrm{~W} /(\mathrm{m} \cdot \mathrm{K}))$ were lower than the estimated values, which are in the range 225 to $305 \mathrm{~W} /(\mathrm{m} \mathrm{K})$, based on their true porosities (ratio of void volume to sample volume) of 24.7 to $50.9 \%$ and the thermal conductivity of bulk silver at $406 \mathrm{~W} /(\mathrm{m}$ $\mathrm{K})$. One possible reason is the presence of interfacial resistances, i.e., thermal resistance at the $\mathrm{SiC}$ diode/sintered layer and sintered layer/ $\mathrm{Cu}$ interfaces. It is presumed that the interfacial resistance for true Ag-Ag contact at the interfaces would be much lower than for silver particles in the sintered layer, so during power cycling inter-particle diffusion of $\mathrm{Ag}$ could be expected to occur [29]. On the other hand, the appearance of cracks/voids due to nanosilver particles forming Ag crystals, continued densification and delamination during power cycling (mainly due to CTE mismatch) may eventually 
lead to a degradation in performance of the sintered die attachments.

It is interesting to note that the crack growth data (Fig. 13) accurately mirrors the observed evolution of thermal conductivity in Fig. 5, for all samples. Before 100k cycles, sample W4, with a denser microstructure (true porosity of $24.7 \%$ ) maintains its thermal performance. This can be attributed to the aforementioned trade-off between the thermal resistance changes from continued post-sintering and the appearance of vertical cracks/voids [14]. After 100k cycles, the sudden decrease in the effective thermal conductivity can be ascribed to local delamination as observed in the X-ray CT images (see Fig. 9d). During this stage post-sintering densification has virtually stabilized and local delamination occurs due to the thermal stress caused by the CTE mismatch between the die and the substrate. The occurrence of localized delamination is accelerated and terminated by neighbouring vertical cracks. Localized delamination results in a reduction in the effective thermal conductivity to a greater extent than that associated solely with the development of vertical cracks. This may explain why the effective thermal conductivity values decrease at a practically constant rate, with increasing power cycles, despite the marked decline in the rate of increase in the percentage of cracked area (Fig. 13) above 230k cycles.

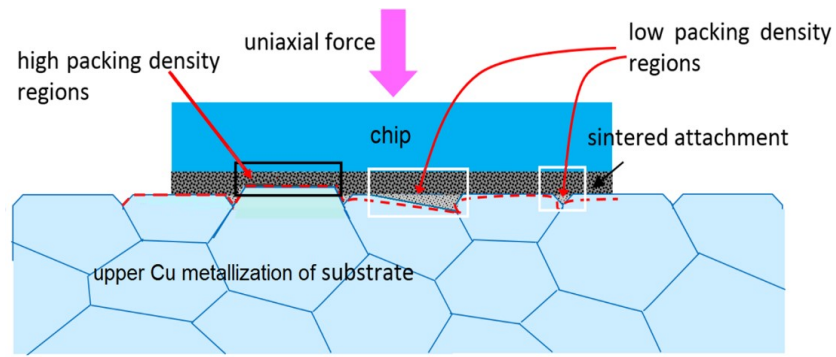

Fig.12. Schematic of sintered die attachment regions with contrasting localised packing densities

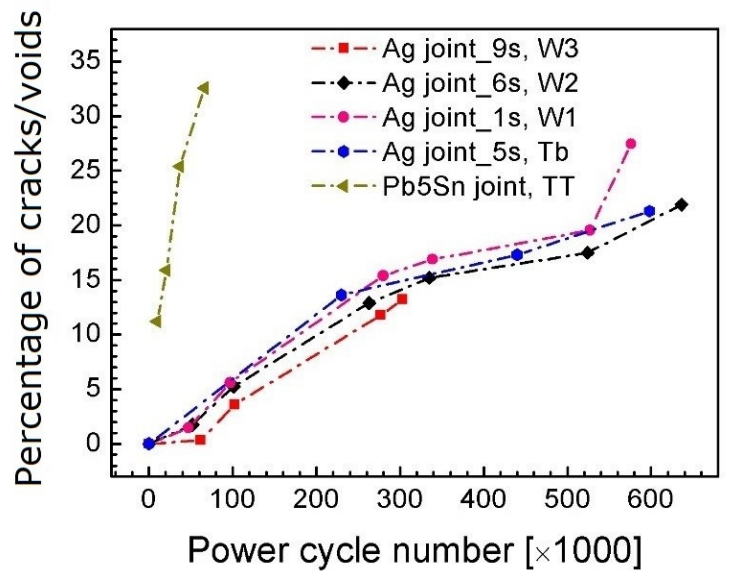

Fig. 13. Evolution of the percentage of cracks/voids of die attachments during power cycling.

For the Pb5Sn solder joints, the effective thermal conductivity decreases linearly while the percentage of voids/cracks increases (linearly) with increasing power cycles. However, the rate of decrease in the former was much higher than the latter. This can be attributed to the fact that more significant local delamination occurs at the die/solder and/or the solder/Cu interfaces as the power cycling tests proceed; such delamination having a more pronounced impact on thermal conductivity than voids/cracks. This is supported by the incidence of features (voids/cracks) which are larger/wider at interfaces than in the central areas; see Figs. 14c and 14d.

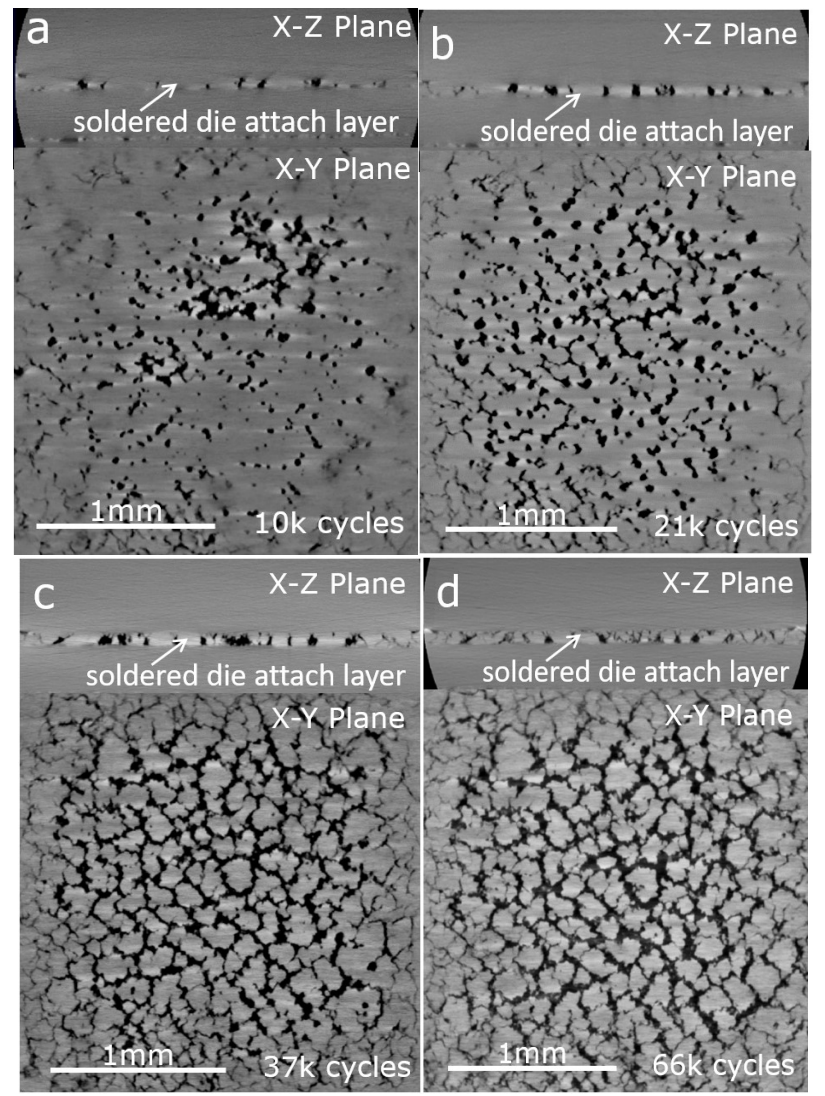

Fig. 14. Virtual X-ray cross-sectional images obtained from the $\mathrm{Pb} 5 \mathrm{Sn}$ joint showing the microstructural evolution: (1) after $10 \mathrm{k}$ cycles, (b) after $21 \mathrm{k}$ cycles, (c) after $37 \mathrm{k}$ cycles, and (d) after $66 \mathrm{k}$ cycles.

\section{Correlation between sintering processes and reliability}

The relationship between shear strength/porosity and power cycling lifetime is illustrated in Fig. 15. It illustrates that higher shear strength and/or low microstructural porosity infers a longer lifetime. In other words, the lifetime of joints can be significantly improved by enhancing the shear strength, and/or lowering the apparent true porosity. The shear strength/density, in general, increases with increasing sintering temperature, pressure and time across the experimental design parameters used, as reported in our previous study [31]. Therefore, it can be concluded that using increased sintering temperature, pressure and time implies sintered joints with improved lifetimes. However, there is clearly an opportunity to trade off expected lifetime against processing time and cost without significantly compromising reliability. In particular, comparing samples W1 and $\mathrm{W} 4, \mathrm{~W} 1$ has a process cycle time of just 1s and a lifetime 
that is 5 times that of the Pb5Sn sample whereas $\mathrm{W} 4$ has a cycle time of $9 \mathrm{~s}$ and a lifetime some 14 times that of the $\mathrm{Pb} 5 \mathrm{Sn}$ sample.

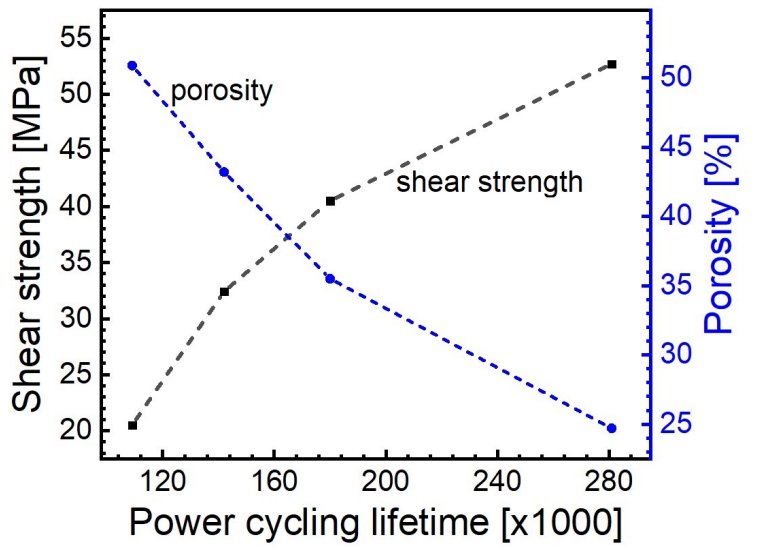

Fig. 15. Relationship between shear strength, microstructural porosity and power cycling lifetime for sintered die attachments.

\section{CONCLUSIONS}

The evolution of the thermal performance and microstructures of nano-silver sintered joints, prepared by time-reduced sintering, together with $\mathrm{Pb} 5 \mathrm{Sn}$ soldered joints, were compared for $\mathrm{SiC}$ diode die attachments subjected to constant temperature-swing power cycling from 50 to $200{ }^{\circ} \mathrm{C}$. Assuming a failure criterion of $20 \%$ decrease in the effective thermal conductivity, the evaluated lifetimes of the sintered joints are $281 \mathrm{k}$ cycles, $180 \mathrm{k}$ cycles, $142 \mathrm{k}$ cycles and $109 \mathrm{k}$ cycles in order of descending shear strength (or density) where the weakest sintered joint is palpably 5 times more reliable than for that of a Pb5Sn soldered joint (20k cycles). The sintered joint with the highest shear strength (higher than52.7 MPa and porosity less than $24.7 \%$ ) exhibited thermal stability up to $100 \mathrm{k}$ cycles, with the effective thermal conductivity decreasing virtually linearly with increasing cycles.

The evolution of thermal performance of the sintered joints is associated with continued thermally-induced densification of Ag, leading to a nominal increase in the thermal conductivity, offset by the appearance of cracks and delamination which results in a decrease in the thermal conductivity. The continued densification of sintered joints (during power cycling) impedes the development of localized delamination with a dependency on the bonding quality of as-prepared joints; the lower the initial porosity the greater the influence. Collectively, the results demonstrate that high reliability sintered die attachments can be created on a die bonder using process times as short as 1 second, opening a route to cost-effective, rapid and flexible manufacturing.

\section{ACKNOWLEDGMENT}

The authors wish to thank Oscar Khaselev and Mike Marczi of Alpha Assembly Solutions for providing Argomax 2020 nanosilver dry film.

\section{REFERENCES}

[1] P. G. Neudeck, R. S. Okojie, and L.-Y. Chen, "High-temperature electronics-a role for wide bandgap semiconductors-A role for wide bandgap semiconductors?," Proceedings of the IEEE, vol. 90, no. 6, pp. 1065-1076, 2002

[2] T. P. Chow and R. Tyagi, "Wide bandgap compound semiconductors for superior high-voltage power devices," in [1993] Proceedings of the 5th International Symposium on Power Semiconductor Devices and ICs, 1993: IEEE, pp. 84-88.

[3] B. J. Baliga, "Power semiconductor device figure of merit for high-frequency applications," IEEE Electron Device Letters, vol. 10, no. 10, pp. 455-457, 1989.

[4] B. Zhao, Q. Song, and W. Liu, "Experimental comparison of isolated bidirectional DC-DC converters based on all-Si and all-SiC power devices for next-generation power conversion application," IEEE Transactions on Industrial Electronics, vol. 61, no. 3, pp. 1389-1393, 2013.

[5] S.-J. Kim, K.-S. Kim, S.-S. Kim, C.-Y. Kang, and K. Suganuma, "Characteristics of $\mathrm{Zn}-\mathrm{Al}-\mathrm{Cu}$ alloys for high temperature solder application," Materials transactions, vol. 49, no. 7, pp. 1531-1536, 2008.

[6] L. A. Navarro et al., "Thermomechanical assessment of die-attach materials for wide bandgap semiconductor devices and harsh environment applications," IEEE transactions on Power Electronics, vol. 29, no. 5, pp. 2261-2271, 2013.

[7] V. R. Manikam and K. Y. Cheong, "Die attach materials for high temperature applications: A review," IEEE Transactions on Components, Packaging and Manufacturing Technology, vol. 1, no. 4, pp. 457-478, 2011.

[8] M. Rettenmayr, P. Lambracht, B. Kempf, and C. Tschudin, "Zn-Al based alloys as $\mathrm{Pb}$-free solders for die attach," Journal of electronic materials, vol. 31 , no. 4 , pp. 278-285, 2002.

[9] H. A. Mustain, W. D. Brown, and S. S. Ang, "Transient liquid phase die attach for high-temperature silicon carbide power devices," IEEE transactions on components and packaging technologies, vol. 33, no. 3, pp. 563-570, 2010.

[10] S. W. Yoon, M. D. Glover, and K. Shiozaki, "Nickel-tin transient liquid phase bonding toward high-temperature operational power electronics in electrified vehicles," IEEE Transactions on Power Electronics, vol. 28, no. 5, pp. 2448-2456, 2012.

[11] B.-S. Lee, S.-K. Hyun, and J.-W. Yoon, "Cu-Sn and Ni-Sn transient liquid phase bonding for die-attach technology applications in high-temperature power electronics packaging," Journal of Materials Science: Materials in Electronics, vol. 28, no. 11, pp. 7827-7833, 2017.

[12] J. Kahler, N. Heuck, A. Wagner, A. Stranz, E. Peiner, and A. Waag, "Sintering of copper particles for die attach," IEEE Transactions on Components, Packaging and Manufacturing Technology, vol. 2, no. 10, pp. 1587-1591, 2012.

[13] Z. Zhang and G.-Q. Lu, "Pressure-assisted low-temperature sintering of silver paste as an alternative die-attach solution to solder reflow," IEEE Transactions on electronics packaging manufacturing, vol. 25, no. 4, pp. 279-283, 2002.

[14] J. Zhao, M. Yao, and N.-C. Lee, "Nano-Cu sintering paste for high power devices die attach applications," in 2018 IEEE 68th Electronic Components and Technology Conference (ECTC), 2018: IEEE, pp. 557-563.

[15] F. Yu, R. W. Johnson, and M. C. Hamilton, "Pressureless sintering of microscale silver paste for $300 \mathrm{C}$ applications," IEEE Transactions on Components, Packaging and Manufacturing Technology, vol. 5, no. 9, pp 1258-1264, 2015.

[16] H. Schwarzbauer, "Method of securing electronic components to a substrate," ed: Google Patents, 1989.

[17] P. Peng, A. Hu, A. P. Gerlich, G. Zou, L. Liu, and Y. N. Zhou, "Joining of silver nanomaterials at low temperatures: processes, properties, and applications," ACS applied materials \& interfaces, vol. 7, no. 23, pp. 12597-12618, 2015.

[18] J. G. Bai, J. N. Calata, and G.-Q. Lu, "Processing and characterization of nanosilver pastes for die-attaching SiC devices," IEEE Transactions on electronics packaging manufacturing, vol. 30, no. 4, pp. 241-245, 2007.

[19] K. S. Siow, "Are sintered silver joints ready for use as interconnect material in microelectronic packaging?," Journal of electronic materials, vol. 43, no. 4, pp. 947-961, 2014.

[20] A. A. Wereszczak, D. J. Vuono, Z. Liang, and E. E. Fox, "Sintered silver joint strength dependence on substrate topography and attachment pad 
geometry," in 2012 7th International Conference on Integrated Power Electronics Systems (CIPS), 2012: IEEE, pp. 1-6.

[21] C. Buttay et al., "Die attach of power devices using silver sintering-bonding process optimisation and characterization," Additional Papers and Presentations, vol. 2011, no. HITEN, pp. 84-90, 2011.

[22] H. Zheng, K. D. Ngo, and G.-Q. Lu, "Temperature cycling reliability assessment of die attachment on bare copper by pressureless nanosilver sintering," IEEE Transactions on Device and Materials Reliability, vol. 15, no. 2, pp. 214-219, 2015.

[23] T. Wang, X. Chen, G.-Q. Lu, and G.-Y. Lei, "Low-temperature sintering with nano-silver paste in die-attached interconnection," journal of electronic materials, vol. 36, no. 10, pp. 1333-1340, 2007.

[24] K. S. Siow, "Mechanical properties of nano-silver joints as die attach materials," Journal of alloys and compounds, vol. 514, pp. 6-19, 2012.

[25] J. Dai, J. Li, P. Agyakwa, and C. M. Johnson, "Time-efficient sintering processes to attach power devices using nanosilver dry film," Journal of Microelectronics and Electronic Packaging, vol. 14, no. 4, pp. 140-149, 2017.

[26] M. Knoerr, S. Kraft, and A. Schletz, "Reliability assessment of sintered nano-silver die attachment for power semiconductors," in 2010 12th Electronics Packaging Technology Conference, 2010: IEEE, pp. 56-61.

[27] N. Heuck et al., "Aging of new interconnect-technologies of power-modules during power-cycling," in CIPS 2014; 8th International Conference on Integrated Power Electronics Systems, 2014: VDE, pp. $1-6$.

[28] J. G. Bai and G.-Q. Lu, "Thermomechanical reliability of low-temperature sintered silver die attached $\mathrm{SiC}$ power device assembly," IEEE Transactions on device and materials reliability, vol. 6, no. 3, pp. 436-441, 2006

[29] J. Dai, J. Li, P. Agyakwa, M. Corfield, and C. M. Johnson, "Comparative thermal and structural characterization of sintered nano-silver and high-lead solder die attachments during power cycling," IEEE Transactions on Device and Materials Reliability, vol. 18, no. 2, pp. 256-265, 2018

[30] J. Dai, J. Li, P. Agyakwa, and C. M. Johnson, "Power cycling reliability of time-reduced sintering for attaching $\mathrm{SiC}$ diodes using nanosilver film," in CIPS 2018; 10th International Conference on Integrated Power Electronics Systems, 2018: VDE, pp. 1-6.

[31] J. Dai, J. Li, P. Agyakwa, M. Corfield, and C. M. Johnson, "Shear strength of die attachments prepared using dry nanosilver film by a time-reduced sintering process," Microelectronics Reliability, vol. 111, p. 113740, 2020.

[32] G. Chen et al., "Transient thermal performance of IGBT power modules attached by low-temperature sintered nanosilver," IEEE Transactions on Device and Materials Reliability, vol. 12, no. 1, pp. 124-132, 2011

[33] E. N. Landis and D. T. Keane, "X-ray microtomography," Materials characterization, vol. 61, no. 12, pp. 1305-1316, 2010.

[34] S.-J. L. Kang, Sintering: densification, grain growth and microstructure. Elsevier, 2004. 